\title{
LENGUA, CONFLICTO Y VIOLENCIA
}

Reflexiones en torno a un discurso andino

\section{Juan Carlos Godenzzi}

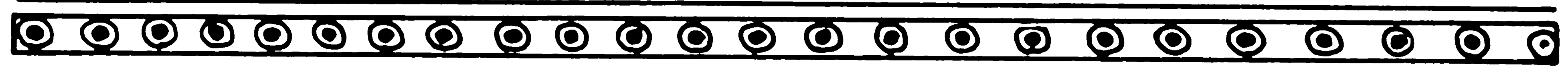

EL LENGUAJE no es sólo una actividad puesta al servicio del conocimiento y la comunicación; es, igualmente, un instrumento de poder que actúa al interior de una sociedad y en las relaciones interpersonales. Así, hablar quiere decir, al mismo tiempo, objetivar el mundo referencial, decir algo a otro e instaurar lazos ya sea de cohesión o de discrimen social.

En lo que se refiere al Perú, nuestra realidad geográfica y social es "aprehendida" bajo los signos de lenguas particulares: el castellano, el quechua, el aymara y otras numerosas lenguas existentes en nuestro territorio. Estas mismas lenguas posibilitan la comunicación o la obstaculizan. Finalmente, entre estas lenguas se estąblecen relaciones asimétricas de poder, adquiriendo cada una un determinado estatus socio-político.

En el presente artículo nos ocuparemos de un discurso sobre el conflicto y la violencia y que constituye, al mismo tiempo, un ejemplo de lengua discriminada. Haré 
unas reflexiones sobre el discurso mismo, su enunciador y su manifestación lingüística.

\section{$1-$ EL DISCURSO}

“(1) Algunos este ... hm ... este los que trabajan ... en ... hm empresa SAIS ... en la hacienda Jaya ... han sufrido como siete familias ... (2) y todos los ... ehh ... afiliados o socios de la empresa con la dirección de gerente general o ... personeros ... o ... presidente de la ... SAIS lo hicieron quimar ehh siete familias sus casas (3) porque ... esas siete familias no quisieron pertenecer a la empresa (4) porque la empresa di un principio dijeron de que es voluntario pertenecer o no pertenecer, así dijeron; (5) pero en esa parte ellos ignora ... en esa parte ellos no informaron bien porque era a fuerzas. (6) Entonces esas siete personas no quisieron pertenecer; $(7)$ pero de cuatro esquinas sus casitas todo lo han tumbado al suelo ... entonces después lo quiman.

(8) Después una señora estaba dando luz. (9) Hace tres días estaba en la cama y el bibi que recién nacido y la mujer gritando, lo agarra al bibi y lo golpea a una ... sobre una piedra; (10) el bibi muere al instante. (11) E la señora grita: ipor siquiera amor a Dios, no me hagan así ...! (12) entonces di una frazada lo saca fuera (13) entonces así lo quimaron esos dirigentes de la empresa ... en empresa SAIS Rosaspata. (14) En ahí ... ehh en ahi no existe en las empresas como humanos o como ... como que la persona tiene dignidad sino que en esa forma lo abis ... lo abusan en todas partes; (15) hace represión. (16) Los animales también se lo han quitado y se lo han comido ... se han dividido sus animales. (17) En la ficha actual no tienen ni siquiera ni plata para difindirse (18) y llorando los pobres en el mismo logar ... 
(19) porque ellos son nacidos en el mismo logar.

(20) ¿dónde querían botarlo?

(21) ¿qué querían hacerlo con esta clase de represión?

(22) ¡Así ... unos hermanos que hagan así!

(23) Eso quería infirmar ... esto ... informarlo, compañeros".

\section{Circunstancias}

Este relato fue recogido en el Departamento de Puno, en 1978. Su "productor" o enunciador era un hombre de 47 años de edad, natural del distrito de Moho (Provincia de Huancané), de situación económica modesta, con pocos años de escuela y de origen campesino aymara. Su primera lengua fue el aymara; posteriormente aprendió el castellano. El "escenario" de este discurso fue una asamblea de comunidades aymaras y quechuas que se proponían realizar algunas acciones en común; el total de participantes alcanzaba a unas 70 personas, además de algunos invitados y observadores que sólo hablaban castellano. La comunidad anfitriona fue la de Cachipucara (Distrito de Pilcuyo, Provincia de Chucuito).

Es en el momento consagrado a los informes, en que cada delegado presentaba los problemas de su comunidad, cuando este discurso fue dicho en castellano.

\section{Trama semántica}

Podemos jerarquizar los significados que se desprenden de los distintos fragmentos, hasta llegar al significado global: La mala información por parte de la SAIS y el mal entendimiento por parte de las siete familias efectivi- 


\section{CUADRO: TRAMA SEMANTICA}

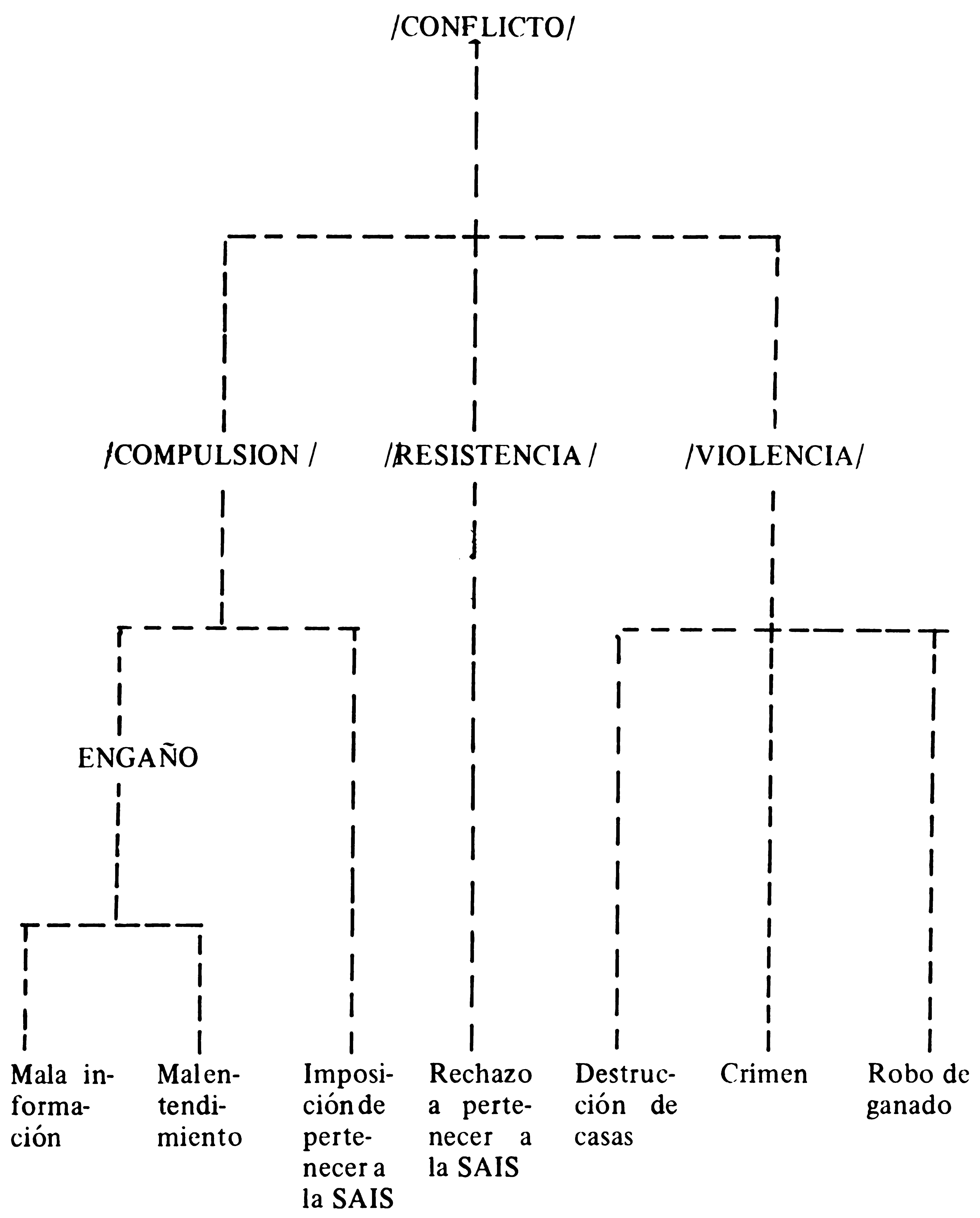


zan el engaño, el cual, sumado a la imposición de anexarse a la empresa ("porque era a fuerzas"), constituyen el significado /COMPULSION/. El rechazar la pertenencia a la empresa configura el significado /RESISTENCIA/. La destrucción de las casas, el asesinato de la criatura y el robo del ganado se integran dentro del significado /VIOLENCIA/. Finalmente, los significados /COMPULSION/, /RESISTENCIA/ y /VIOLENCIA/ se subsumen dentro de un significado mayor que es el de /CONFLICTO/.

En efecto, el problema de la economía campesina, la lucha en torno a la tierra y los desbordes de violencia constituyen expresiones de una situación conflictiva como la de la región andina.

Esta trama semántica podría ser graficada, tal como aparece en el cuadro.

Organización del discurso

Analicemos la organización misma del discurso. Para ello vamos a echar mano de lo que algunos especialistas señalan como elementos constitutivos de toda narrativa oral bien formada: una orientación, una complicación de la acción, una evaluación, una resolución y una coda (cf. Labov y Waletzky 1967; Lavandera 1985: 142).

a) Orientación: Está dada por las partes (1) y (2). Se da un resumen o abstract muy suscinto y se especifica el lugar (hacienda Jaya) y los participantes (siete familias / miembros de la SAIS). Constitiyen la introducción del discurso.

b) Complicación de la acción: Es la secuencia propiamente narrativa: la empresa no informó bien: (4) y (5); las siete familias no quisieron integrarse a la empresa: (3) y 
(6); los de la empresa derriban y queman las casas (7); el bebé es golpeado contra una piedra (9) y muere (10); la señora grita (11); el cadáver del bebé es sacado fuera de la casa (12); los de la empresa confiscan y se reparten el ganado (17).

c) Evaluación: Son las cláusulas no narrativas y que, sin hacer avanzar la narración, la comentan. Así, el enunciador lamenta la falta de humanidad y el abuso: (14) y (15); apoya el derecho de las siete familias a sus tierras, argumentando que son nacidas en ese mismo lugar (19); condena los hechos sucedidos, recurriendo a dos preguntas: (20) y (21) y a una exclamación (22).

d) Resolución: Las acciones concluyen con la derrota de las siete familias y su impotencia para defenderse: (17) y (18).

e) Coda: Está dada por la cláusula (23). Constituye la justificación de toda la narración: informar sobre estos sucesos violentos a los compañeros reunidos en la asamblea.

\section{Reglas del juego discursivo}

Todo discurso está regido, aunque muchas veces no lo advirtamos, por ciertas reglas generales. Paul Grice (1975) nos habla del "Principio de Cooperación" (Cooperative Principle) según el cual la comunicación entre dos o más personas compromete a una especie de transacción, pudiendo formularse así: "Que su contribución discursiva corresponda a aquello que es exigido de Ud."

Tal principio, siempre según Grice, contiene cuatro Máximas más específicas:

a) Máxima de Cantidad: "Que su contribución contenga tanta información como sea requerida". 
b) Máxima de Calidad: "Que su contribución sea veraz".

c) Máxima de Relación: "Que su contribución hable de lo que sea relevante".

d) Máxima de Manera: "Sea claro, breve y metódico" (cf. Grice 1975; Lozano y otros 1982: 215 y ss.; Lavandera 1985: 95-99).

Veamos como estas cuatro máximas regulan nuestro discurso:

a) Cantidad: El discurso no contiene ni más ni menos de la información requerida; no se expande, por ejemplo, sobre la importancia y el significado que tiene la tierra para los campesinos, ni sobre los vericuetos legales de la Reforma Agraria. El conocimiento que comparten todos sobre la problemática agraria presupone mucha información que, de explicitarse, sería innecesaria.

b) Calidad: El discurso se esfuerza por dar la información más objetiva posible y por aparecer verdadero. Para ello apela a recursos lingüísticos: modo indicativo; el tiempo de la narración (pretérito); uso de la tercera persona, marcándose más distancia entre el enunciador y los hechos.

c) Relación: En el momento dedicado a los informes, este discurso resulta especialmente relevante; constituye una denuncia a la violencia con que la SAIS "Rosaspata" intenta expandirse a costa de campesinos comuneros o parceleros. Este es el núcleo del mensaje que se quiere transmitir. Otros detalles o consecuencias de estos hechos no son contados, pues no vendrían al caso en ese momento.

d) Manera: El discurso resulta claro para sus destinatarios. Si bien el castellano utilizado es un tanto "imperfecto" en su manifestación, el discurso guarda una cohesión y coherencia interna que asegura la comprensión y concita el interés de toda la audiencia. Por lo demás, es 
breve y bien organizado, poseyendo todos los elementos de una narrativa bien formada.

\section{$2-$ EL ENUNCIADOR}

Todo discurso es siempre, de alguna manera, manifestación del YO que enuncia. El discurso que analizamos finge distanciarse de su "productor" para aparecer como más objetivo y veraz. ¿De qué manera podemos acceder al enunciador a partir de su propio discurso? ¿adopta alguna actitud o pensamiento crítico ante los hechos que relata?

\section{Estrategia en favor de la objetividad}

En el discurso se hace evidente el esfuerzo por permanecer en la aseveración de hechos, creando una atmósfera de objetividad. Pero esta misma operación es ya una muestra de la presencia del enunciador. La estrategia de la aseveración suele ser la manifestación más frecuente de la presencia del enunciador en la anunciación (cf. Benveniste 1970; Lozano y otros 1982: 105). En la parte propiamente narrativa, nuestro autor pretende reducir su presencia, recurriendo a ciertos expedientes lingüísticos que crean un distanciamiento entre el enunciador y su relato: el modo indicativo, las formas verbales del pretérito, el predominio de la tercera persona. Así, pues, aun en los enunciados descriptivos o asertivos podemos encontrar la modalización, es decir "todo aquello que en el texto indica una actitud del sujeto respecto a lo que enuncia, tanto a través del modo verbal, la construcción sintáctica (como en las interrogaciones) o los lexemas (sustantivos, adjetivos, verbos o adverbios) afectivos o evaluati- 
vos" (Lozano y otros 1982: 104). De este modo, podemos decir que la actitud "aseverativa" que asume el autor sobre su producción discursiva tiene como finalidad el asegurarnos que los hechos han sucedido realmente y que no cabe dudar de su veracidad. El enunciador se constituye en garante de los acontecimientos que narra; su discurso lo compromete y su palabra está en juego.

\section{Actitud emotiva}

La dramaticidad de los hechos "objetivos" que narra hacen que el enunciador se vaya implicando cada vez más con ellos; empieza a participar afectivamente. $\mathrm{Y}$ esto se expresa, necesariamente, a través de formas lingüísticas:

Veamos el tiempo verbal. Del pretérito, tiempo de la narración, que expresa una mayor distancia del sujeto, se pasa al pretérito perfecto, tiempo que expresa la relación "viva" entre el sujeto y los hechos; y, más aún, al presente, tiempo que nos hace aparecer un evento como contemporáneo al momento mismo de la enunciación (cf. Benveniste 1959; Weinrich 1968; Lozano y otros 1982: 103109). Los hechos más dramáticos son contados recurriendo al pretérito perfecto: (7) (16), y al presente: (9) (10) (11) (12) (17).

Si prestamos atención a la persona gramatical, observamos que las secuencias narrativas usan la tercera persona; sin embargo, en la parte emotiva (11), el autor pasa al estilo directo $y$ hace que la señora interpele en segunda persona a sus agresores: “ ipor siquiera por amor a Dios, (Uds.) no me hagan así ...!". Este cambio hace que uno ingrese más en los hechós, como si los estuviera viendo.

Otras marcas afectivas las tenemos en el sustantivo en diminutivo casitas (7) y en el adjetivo sustantivado los 
pobres (18) que expresan afecto y compasión hacia las siete familias.

\section{Juicio valorativo}

De una manera más explícita, el enunciador hace comentarios valorativos en las cláusulas (14), (15), (19), (20), (21) y (22). Denuncia de un modo muy claro el crimen, los atropellos y la falta de respeto a la vida humana; toma partido en favor de las siete familias y se indigna contra los agresores. Es en la cláusula (22) donde el enunciatario alcanza el punto más alto de su indignación con una exclamación tan teñida de subjetividad y emotividad que se da un cambio en el modo verbal: del modo indicativo se pasa, por única vez, al modo subjuntivo: “ ¡así... unos hermanos que hagan así!".

Tal exclamación sintetiza un juicio lúcido sobre la violencia: uno no puede permanecer indiferente y pasivo ante estos hechos; pero tampoco se trata de condenar irremediablemente a los agresores: ellos no dejan de ser humanos, personas y, más aún, "hermanos", aunque sus actos sean repudiables. Nos dice que lo que está sucediendo no es normal, no corresponde a la calidad humana. El juicio del enunciador dibuja una perspectiva: cabe esperar una situación diferente donde se logre mayores niveles de humanización.

\section{3 - UNA LENGUA DISCRIMINADA}

Para decir su discurso, el enunciador elige el castellano, lengua que él mismo y gran parte de su auditorio conocen imperfectamente. ¿Por qué no ha escogido su lengua materna; el aymara? Se podría pensar que busca 
un cierto prestigio frente a los campesinos. Pero al mismo tiempo algunos de los enunciatarios tienen el castellano como primera lengua. ¿No corre entonces el riesgo de ser criticado por ellos y perder todo prestigio? Lo que prima para él es que el relato de los acontecimientos tan graves que han ocurrido sea escuchado por el mayor número posible de personas. Es un hecho que aquellos que hablan quechua o aymara comprenden un cierto nivel de castellano, siendo lo contrario mucho más raro. El temor de una pérdida de prestigio, entonces, llega a ser para él algo secundario. La atmósfera de solidaridad y compañerismo que rige la asamblea facilita la decisión en favor del castellano.

Si analizamos esta lengua tal como es utilizada por el enunciador, podemos señalar algunas de sus características.

Imprecisión vocálica.- Las fronteras entre las vocales /e/, /i/ y entre /o/, /u/ no son muy nítidas. Así, por ejemplo, encontramos quimar por quemar (2); bibi por bebé (9); ficha por fecha (17); logar por lugar (18 y 19). El sistema vocálico del aymara, así como el del quechua, tiene tres fonemas; al pasar al castellano, que tiene cinco, surge la imprecisión (cf. Escobar 1978: 86-89).

Flexibilidad en la concordancia.- Consideremos la siguiente secuencia: "los animales también se lo han quitado y se lo han comido... se han dividido sus animales" (16). Advertimos que el pronombre lo (singular) no concuerda en número con el sustantivo los animales (plural). Esto mismo ocurre en las secuencias (19) y (20): "porque ellos son nacidos en el mismo logar ¿donde querían botarlo?". En aymara, la concordancia no es obligatoria y este hecho probablemente interfiere cuando se pasa al castellano. 
Atribución de nuevas funciones a una forma.- $A l$ interpretar algunas secuencias, surgen algunas ambigüedades. En "¿qué que

Atribución de nuevas funciones a una forma.- $\mathrm{Al}$ interpretar algunas secuencias, surgen algunas ambigüedades. En "¿qué querían hacerlo con esta clase de represión?" (21), ¿qué función desempeña la forma lo? ¿es pronombre de objeto directo, de objeto indirecto (sustituyendo a les) o simple refuerzo verbal? Esto mismo cabe preguntarse en la secuencia: "Eso quería infirmar... esto... informarlo, compañeros" (23). Podríamos postular que lo es una forma polivalente que, eventualmente, podría desempeñar cualquiera de esas tres funciones. (Para una mayor discusión al respecto, cf. Godenzzi 1986: 187-201).

Estos rasgos, añadidos a otros de carácter entonacional y de dicción, tipifican un castellano adquirido como segunda lengua a partir del quechua o del aymara. Esta variedad posibilita una expresión y comunicación idónea, tal como nuestro enunciador lo ha hecho con respecto a sus enunciatarios; puesto que pertenecen al mismo pueblo "social", pueden muy bien entenderse, interpelarse y comunicarse satisfactoriamente. En un sentido estrictamente lingüístico, todas las variedades (regionales o sociales) de una lengua son equivalentes, pues con cualquiera de ellas puedo producir mi discurso. Sin embargo, en un sentido social y político, cada lengua y cada una de sus variedades adquiere un estatus determinado.

El conjunto de las lenguas habladas en el Perú constituye un espacio sociolingüístico donde ciertas variedades del castellano gozan de poder y prestigio y son utilizadas en los asuntos públicos y oficiales, mientras que otras variedades del castellano ("motosas") y otras lenguas (aymara, quechua, etc.) son reducidas a usos locales o domésticos y resultan "oprimidas", objeto de menosprecio 
y discrimen. A este desequilibrio conflictivo en cuanto al poder, el reconocimiento social y la repartición funcional de las lenguas se le denomina diglosia (cf. Ninyoles 1976: 152; y 1978: 30-36; Mackey 1976: 29).

La situación de las lenguas en el Perú nos revela que constituimos una sociedad diglósica, profundamente marcada por jerarquías, desigualdades y exclusiones; $y$, por tanto, atravesada por el conflicto y susceptible de generar violencia.

Al hablarnos sobre la situación conflictiva y violenta del Altiplano, el enunciador actualiza, al mismo tiempo, el campo lingüístico diglósico peruano, al interior del cual su castellano "motoso" ocupa una posición subordinada y él mismo se convierte en agente compelido a la sumisión y expuesto a la burla social. Descubrimos que también en el dominio de los signos del lenguaje se ejerce, con frecuencia clandestinamente, el poder, el conflicto y la violencia.

\section{EPILOGO}

El discurso analizado se refiere a eventos sucedidos en 1978, en el contexto histórico particular de la Reforma Agraria, bajo el régimen militar del Gral. Francisco Morales Bermúdez. Posteriormente, el conflicto entre las grandes empresas asociativas (SAIS) y las comunidades campesinas se agudiza; las primeras entran en un proceso de reestructuración a partir de 1986. De otra parte, aparece un elemento nuevo: las acciones de brutal violencia por parte del senderismo. Uno de los últimos actos graves se dio el 27 de Febrero en el poblado de Canayre, a $250 \mathrm{kms}$. en la selva norte de Ayacucho, donde elementos senderistas disfrazados de militares "asesinaron a 39 campesinos, en- 
tre ellos a una bebé de tres meses" (Revista Caretas, No. 1047, Lima 6.3.89, p. 84).

Frente a la violencia de toda clase, la socio-política, la cultural, la que se ejerce físicamente o a través de los signos de una lengua, el "juicio" de nuestro enunciador tiene vigencia y cobra vital importancia: se trata de reducir o abolir el conflicto y la violencia con las armas de una mayor humanización. 


\section{Referencias Bibliográficas:}

BENVENISTE, Emile:

1959

"Les relations de temps dans le verbe français", Bulletin de la Sociètè de Linguistique, LIV, fasc. 1. París.

1970

"L'appareil formel de l'énonciation"; Langages, 17. París.

ESCOBAR, Alberto:

1978

Variaciones sociolingüisticas del castellano en el Perú. Instituto de Estudios Peruanos. Lima.

GIORDAN, Henri y Alain RICARD:

1976 Diglossie et littérature. Bordeaux Talance Maison des Sciences de L'Homme.

GODENZZI, Juan Carlos:

1986

"Pronombres de objeto directo e indirecto del castellano en Puno", en Lexis vol. X, No. 2. PUC. Lima pp. 187 - 201.

GRICE, H. Paul:

"Logic and conversation", Syntax and Se- 
mantics, vol. III, Speech Arts, ed. por P. Cole y J.L. Morgan, Academic Press, Inc., pp. 41-58.

LABOV, W. y J. WALETZKY:

1976

"Narrative analysis: Oral versions of personal experience", en June Helms (ed.), Essays on the Verbal and Visual Arts. Seattle \& London, University of Washington Press, pp. 12-44.

LAVANDERA, Beatriz R.:

1985 Curso de Lingüistica para el Análisis del Discurso. Bibliotecas Universitarias. Buenos Aires.

LOZANO, Jorge, Cristina PEÑA-MARIN y Gonzalo ABRIL:

1982

Análisis del discurso. Hacia una semiótica de la interacción textual. Ediciones Cátedra. Madrid.

MACKEY, William F.:

1976

"Langue, dialecte et diglossie littéraire", en H. Giordan y A. Ricard. 1976: 19-50.

NINYOLES, Rafael, Ll:

1976 "Ideologies diglossiques et assimilation", en H. Giordan y A. Ricard 1976: 151-160.

1980 Idioma y poder social. Editorial tecnos. Madrid.

WEINRICH, H.:

1968

Estructura y función de los tiempos en el lenguaje. Gredos. Madrid. 